\title{
The effect of pentoxifylline on L-1 sarcoma tumor growth and angiogenesis in Balb/c mice
}

\author{
BARBARA JOANNA BAEAN ${ }^{I}$, URSZULA DEMKOW², PIOTR SKOPIŃSKI \\ MAŁGORZATA BYCHAWSKA4 ${ }^{4}$ EWA SKOPIŃSKA-RÓŻEWSKA ${ }^{5}$, SŁAWOMIR LEWICKI ${ }^{5}$, \\ ROBERT ZDANOWSKI
}

${ }^{1}$ Department of Immunology, Biochemistry and Nutrition, Warsaw Medical University, Poland

${ }^{2}$ Department of Laboratory Diagnostics and Clinical Immunology of Developmental Age, Warsaw Medical University, Poland

${ }^{3}$ Department of Histology and Embryology, Center for Biostructure Research, Warsaw Medical University, Poland

${ }^{4}$ Central Laboratory Warsaw, DIAGNOSTYKA Ltd, Krakow, Poland

${ }^{5}$ Military Institute of Hygiene and Epidemiology, Warsaw, Poland

\begin{abstract}
Methyloxantines are present in many herbs and vegetal foods, among them in tea, coffee and chocolate. Previous studies revealed that theophylline and theobromine have anti-angiogenic properties. Anti-tumor properties of theobromine were also described. Pentoxifylline (3,7-dimethyl-1-(5-oxohexyl) xanthine, PTX) is a synthetic xanthine derivative. It is a phosphodiesterase inhibitor and has various anti-inflammatory abilities. Pentoxifylline is widely used in therapy of inflammatory arterial diseases such as intermittent claudication of upper and lower limbs as well as in coronary heart disease.

The aim of our research was to evaluate the effect of pentoxifylline (individually and in combination with non-steroidal anti-inflammatory drug sulindac), on L-1 sarcoma angiogenic activity and tumor formation in syngeneic Balb/c mice.

Pre-incubation of tumor cells for 90 min with various PTX concentrations resulted in dose-dependent decrease of their ability to induce newly-formed blood vessels after transplantation into the skin of recipient mice. Administration of PTX to mice, recipients of tumor cells, slows tumor growth and reduces its volume. Synergistic inhibitory effect of PTX and sulindac, expressed as \% of tumors sixth and thirteen day after subcutaneous grafting of L-1 sarcoma into syngeneic Balb/c mice, was observed.
\end{abstract}

Key words: mice, L-1 sarcoma growth, angiogenesis, pentoxifylline.

(Cent Eur J Immunol 2017; 42 (2): 131-139)

\section{Introduction}

In recent years one can observe the intensification of research efforts to study methods of cancer treatment. Most of the research is dedicated to the study of mechanisms of tumor formation and therapies that entail the blocking of certain stages of tumor progression or changing of the direction of progression. The studies on the processes of angiogenesis are particularly intensive. A number of angiogenesis inhibitors have been described, and clinical trials are conducted in cancer and ophthalmic patients. Most of these substances, however, has a number of side effects. So, again, more attention is paid to angiogenesis inhibitors of natural origin [1].

Methyloxantines are present in many herbs and vegetal foods, among them in tea, coffee and chocolate. Previous studies have shown that theophylline and theobromine, in vitro and in vivo, influenced angiogenesis in various experimental models. In 1993 Skopiński et al. described the inhibitory effect of theophylline and theobromine on the angio- genic activity of blood mononuclear leukocytes of diabetic patients with proliferative retinopathy [2]. In the same time Gil et al have reported inhibition by theobromine tumor-induced angiogenesis in mice [3]. Inhibitory effect of theobromine on induction of angiogenesis and vascular endothelial growth factor (VEGF) mRNA expression in $v$-raf transfectants of human urothelial cells HCV-29 was described by Skopińska-Różewska et al. [4]. Barcz et al. have shown on the model of human ovary cancer that antiangiogenic properties of theobromine are dependent on its interaction with A2 adenosine receptor and inhibition of VEGF production $[5,6]$.

In the present study we would like to investigate if other methyl xanthine derivative - pentoxifylline (PTX), which is widely used in therapy of many so called vascular diseases and possess anti-inflammatory properties has some influence, alone or with non-steroidal anti-inflammatory drug sulindac, on the process of new blood vessels formation during cancer development. Furthermore, we would like find out, whether PTX may influence tumour

Correspondence: Barbara J. Bałan, Department of Immunology, Biochemistry and Nutrition, Warsaw Medical University, Pawińskiego 3 A, 01-106 Warsaw Poland, e-mail: vhm@ post.pl Submitted: 19.03.2017; Accepted: 27.03.2017 
growth, and if sulindac given together with PTX can exert synergistic effect. Both of them have anti-inflammatory properties but the mechanisms of their action are different. Pentoxifylline [3,7-dimethyl-1-(5-oxohexyl)xanthine], is a methyl xanthine derivative known for fibrinolytic activity and its ability to inhibit platelet aggregation and adhesion. It is a phosphodiesterase inhibitor. Because inflammation participates in the pathogenesis and progression of many diseases, it is a widely used as therapeutic agent for inflammatory arterial diseases such as intermittent claudication of upper and lower limbs as well as in coronary heart diseases.

Pentoxifylline regulates the release of proinflammatory cytokines as interleukin $1 \beta$ (IL-1 $\beta$ ), interleukin 6 (IL-6), interleukin 8 (IL-8) and tumor necrosis factor $\alpha$ (TNF- $\alpha$ ) in blood by mononuclear cells, it also suppresses interleukin 2 (IL-2) by inhibition of endogenous TNF $\alpha$. Various studies have shown a favourable effect of PTX and methyloxantine in the course of septic shock, a significant protective effect in infection of Gram-negative sepsis and peritonitis in animal models. Pentoxifylline blocks the inflammatory action of IL- 1 and TNF- $\alpha$ on neutrophils and reduces tissue damage caused by neutrophils in bacterial inflammatory state as septic shock. Additionally, in an experimental model as ischemic injury of intestinal mucosa,
PTX prevents bacterial translocation after intestinal obstruction (ileus). In addition, PTX reduces intestinal bacterial overgrowth, bacterial translocation, and spontaneous bacterial peritonitis in animal (rat) model and reduces oxidative stress in intestinal mucosa [7-9].

Pammi [10] proved that PTX exerts anti-inflammatory action in sepsis and necrotizing enterocolitis in young children. This may explain the beneficial role of pentoxifylline in the prevention of bacterial infection in patients with advanced cirrhosis. Further studies started to highlight that PTX is effective in treating of various clinical conditions including alcoholic hepatitis, or severe acute pancreatitis. Zein et al. demonstrated suppressive effect of PTX on lipid oxidation products in patients with nonalcoholic steatohepatitis [11].

It is widely accepted that endothelial activation and dysfunction are involved in the early development of atherosclerotic and coronary heart diseases. Proinflammatory cytokines, e.g. TNF- $\alpha$ and interferon $\gamma$ (IFN- $\gamma$ ), can induce both endothelial dysfunction and atherosclerosis. The effects of TNF- $\alpha$ in endothelial cells are mediated through $\mathrm{NF}-\kappa \mathrm{B}$. Pentoxifylline was originally discovered as a PDE-1 inhibitor and later it was discovered that also inhibits NF- $\kappa$ B. PTX augments the production of prostacyclins, the vasodilator eicosanoids, and can inhibit the<smiles>C=NC1CNC(=O)NC(=O)C1NC</smiles>

Xanthine<smiles>CNC(=O)N(C(=O)c1c(NC)ncn1C)C(C)(C)O</smiles>

Pentoxifylline

(1-[5-oxohexyl]-3,7-dimetylxanthine)<smiles>C=NC(NC)=C(C(=O)NC)C(=O)N(C)C</smiles>

Theophylline

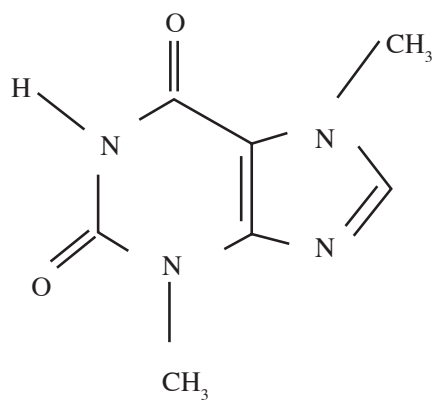

Theobromine

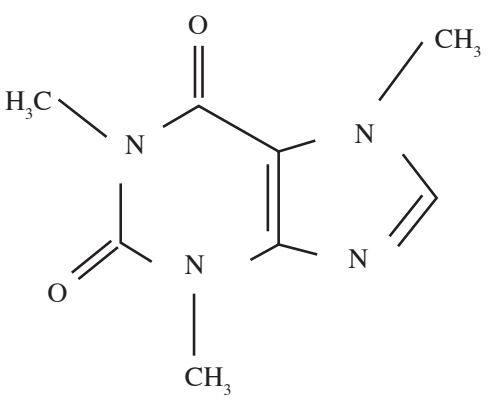

Caffeine

Fig. 1. Xanthine and its derivatives 
production of inflammatory cytokines, thus, reduces neutrophil adhesiveness to endothelial cells, enhances chemotaxis and lowers the production of free radicals that can damage tissues. PTX is known to inhibit phosphodiesterase, an enzyme that breaks down cyclic AMP (cAMP), which elevates the level of intracellular cAMP and, thus, lowers platelet aggregation and depresses the production of TNF- $\alpha$. Pentoxifylline has been reported to promote the oxygenation of ischemic areas and to lower the amount of metabolic derangements associated with ischemia-reperfusion injury. Li et al. [12] showed that PTX plays a protective role in acute inflammatory reaction in the lungs of rodents by attenuating A2A signaling pathways. Furthermore Schulzke et al. [13] observed preventive effect of the drug in bronchopulmonary dysplasia in preterm infants.

Pentoxifylline reduces adhesion molecule expression e.g. soluble levels of vascular cell adhesion molecule-1 (VCAM-1) and interferon- $\gamma$-induced protein (IP-10). VCAM-1 mediates leukocyte adhesion and is linked to endothelial dysfunction, while IP-10 is a chemokine which is described as protein responsible for Th1 immune system activation and endothelial cells apoptosis. The PTX inhibits secretion of IL-12 by macrophages and some IFNs by Th1 cells. Mohammadpour [14] observed a reduction in ICAM-1 and VCAM-1 serum levels after two-month treatment with PTX. Finally, PTX has been studied due to its immunomodulatory properties. Because PTX acts as cAMP-phosphodiesterase's inhibitor it can exert its cellular effects on erythrocytes, platelets, endothelial cells, PMNs, macrophages, and fibroblasts. In this way, PTX reduces the production of inflammatory cytokines by phagocytes and prevents their subsequent effects, such as leukocyte migration, adherence, and degranulation. For this reason, it has been studied alone or as an adjuvant therapy in different conditions, including infectious and carcinogenic processes, and has produced positive effects. As phosphodiesterase inhibitor, PTX reduces superoxide anions responsible for DNA apoptosis and it is effective in reducing damage to specific cell genes (the DNA integrity of the BRCAl tumor suppressor gene and the c-myc proto-oncogene after PTX). Pentoxifylline reduces superoxide anions and inhibits TNF- $\alpha$ responsible for DNA fragmentation and apoptosis or programmed cell death. Furthermore, it may scavenge reactive oxygen species and reduce lipid peroxidation associated with membrane damage and DNA apoptosis in research concerning sperm vitality.

Specialists agree that PTX is well tolerated without adverse effects, and encourage researchers to undertake further clinical and experimental studies elucidation its mechanism of action and to reveal its potential for suggesting novel therapeutic interventions [15-17]. Sunil showed that PTX decreases the number of proinflammatory macrophages expressing COX-2 and MMP-9 also decreased after pentoxifylline, while increases those with anti- inflammatory phenotype $\mathrm{CD} 163^{+}$and $\mathrm{Gal}-3^{+}$. In the light of the previous study it is evident that PTX exerts variable anti-inflammatory effect mediated via numerous parallel mechanisms. However further investigation is warranted to discern all the possible molecular mechanisms of its action.

Historically, anti-inflammatory drugs applied for the relief of pain, inflammation and fever originate from the extracts obtained from the certain plants e.g. Willow Spp. Primarily, they were derivatives of acetyl-salicylic acid like Aspirin, afterwards - chemical advances let the development of the non-steroidal anti-inflammatory drugs (NSAIDs). Initially, most of them were organic acids, but later non-acidic compounds were discovered. There are two cyclooxygenase (COX) enzyme systems, controlling the production of prostanoids. Enzymes cyclooxygenase-1 (COX-1) and -2 (COX-2) metabolize arachidonic acid to prostaglandin $\mathrm{G} 2$ and prostaglandin $\mathrm{H} 2$, which may be converted to other prostaglandins, prostacyclin, and thromboxanes. COX-1, is responsible for production of prostaglandins (PGs) and thromboxane (TxA2) that regulate gastrointestinal, vascular, renal, and other physiological functions, and COX-2 that regulates production of PGs involved in inflammation, fever and pain. COXs cause both beneficial and adverse effects due to the inhibition of prostanoids, which are biologically active derivatives of arachidonic acid released by phospholipase A2 from cell membrane phospholipids. Arachidonic acid is transformed into prostaglandin $\mathrm{H} 2$, through the activity of $\mathrm{COX}-1$ and COX-2 enzymes. Terminal synthases metabolize PGH2 into the biologically active prostanoids, such as prostacyclin (PGI2), prostaglandins PGD2, PGE2 and thromboxane TXA2 (Fig. 2).

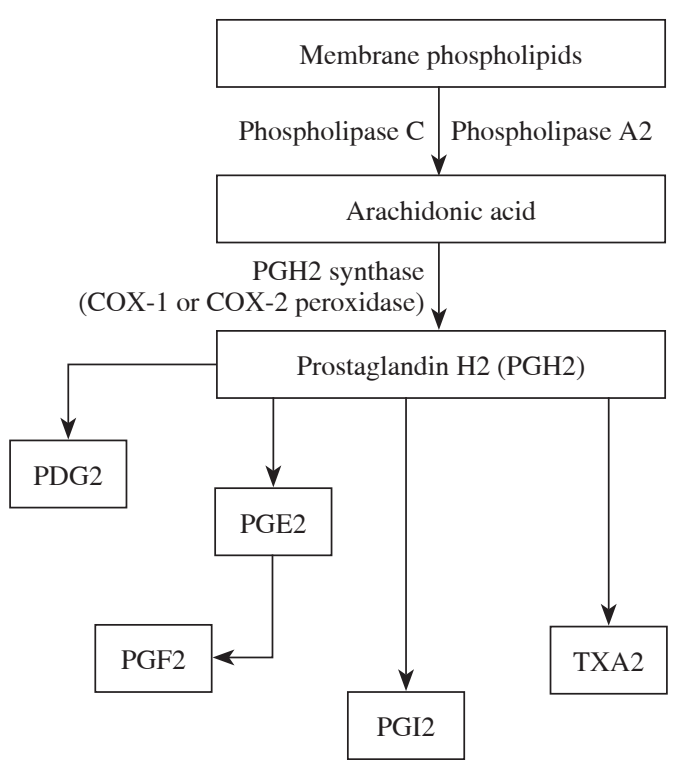

Fig. 2. Scheme of prostaglandin and thromboxane synthesis from arachidonic acid 
COX-1 and COX-2 have the same catalytic activities: cyclooxygenase and peroxidase, although the two isoforms of COX are the products of different genes. COX-2 expression can be rapidly induced by bacterial endotoxin (LPS), some proinflammatory cytokines, tumour necrosis factor alpha (TNF $\alpha$ ), and other growth factors. It is thought, that COX-1 dependent prostanoids play an essential cyto-protective role in gastrointestinal tract, while COX-2-dependent prostanoids play dominant roles in pathophysiologic processes, such as inflammation.

There were two inhibitors of COX-2 known as coxibs (celecoxib and rofecoxib) initially. Clinical trials of several COX-2 selective and nonselective NSAIDs have shown an increased risk of serious cardiovascular and thrombotic events, including ischemic stroke and myocardial infarction.

Therefore, that the inhibitors of COX-2 caused serious cardiovascular events, it is very important to discover why cardiovascular reactions took place with NSAIDs. There are evidences that indicate the main mechanism of action for traditional NSAIDs and selective for COX-2 NSAIDs (coxibs) is the inhibition of COX-2 dependent PGE2. It is suspected also, that coxibs may have antiangiogenic properties and in such way may cause heart ischemia and infarction. Association of myocardial infarctions with COX-2 inhibition may be also related to immunomodulation towards a Th1 response resulting in atheromatous plaque instability. However, it was shown that the cardiovascular hazard is also related to some non-selective NSAIDs, such as diclofenac. In a Danish National Registry study of patients with heart failure, the coxibs and traditional NSAID demonstrated an approximately two-fold increase in hospitalizations for heart failure in COX-2 selective-treated patients and nonselective NSAID-treated patients compared to placebo-treated patients [18-20].

In our research we used Sulindac, which is a non-steroidal, anti-inflammatory indene acetic acid derivative. As a non-steroidal anti-inflammatory drug (NSAID) Sulindac exhibits analgesic, anti-inflammatory, and antipyretic activities in human and in animal models. The mechanism of its action, like that of other NSAIDs, is not completely understood but may be related to prostaglandin synthetase inhibition or it may influence the endothelial cells. In organism Sulindac undergoes two major biotransformations - reversible reduction to the sulfide, and irreversible oxidation to the sulfone (Fig. 3). Biochemical as well as pharmacological evidence indicates that the activity of Sulindac resides in its sulfide metabolite.

\section{Liver enzymes colonic baceria}

It is suggested, that cardiovascular toxicity associated with the administration of NSAIDs selective for COX-2 and some non-selective NSAIDs occurs through a common mechanism involving the inhibition of COX-2-dependent prostacyclin synthesis.

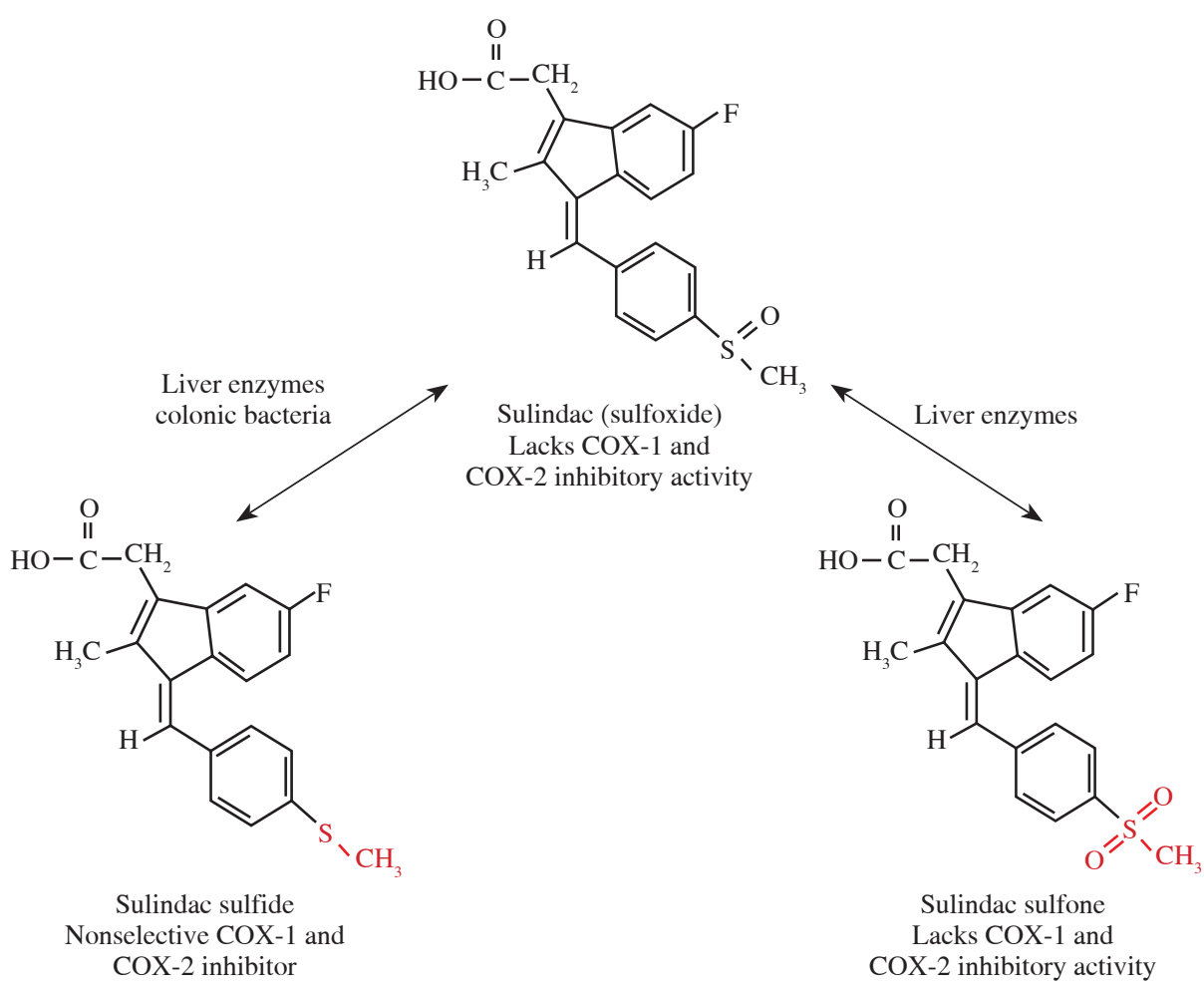

Fig. 3. Metabolism of Sulindac - prodrug transformation by the liver enzymes and bacteria to active metabolites; reduction to sulfide- (reversible in animals and in man) and oxidation to sulfone 
More trials also, reproduction studies in the rat model, with some selective and non-selective NSAIDs show also negative effects on the offspring, decrease in average fetal weight and an increase in numbers of dead pups, and also negative effect on fetal cardiovascular system (closure of ductus arteriosus). It is suggested that their usage during pregnancy (particularly in the late period of pregnancy) should be avoided [21].

\section{Material and methods}

Drugs: Sulindac (Sigma Aldrich) $0.6 \mathrm{mg}$; Pentohexal (Hexal AG Holzkirchen, Germany) $0.5 \mathrm{mg}$; in $40 \mu \mathrm{l} /$ mouse oral daily dose.

Mice: The study was performed on 20-22 g of body mass female, 8-10-weeks old inbred Balb/c mice delivered from the Polish Academy of Sciences breeding colony.

For all performed experiments animals were handled according to the Polish law on the protection of animals and NIH (National Institutes of Health) standards. All experiments were accepted by the local Ethical Committee.

Sarcoma L-1 tumor cells: L-1 sarcoma cells from in vitro culture stock were delivered from Warsaw's Oncology Center collection, passaged in vivo through four generations of locally bred Balb/c mice and grafted subcutaneously for evaluation of tumor growth, or intradermally for evaluation of angiogenic activity in tumor-induced (TIA) cutaneous test, to syngeneic Balb/c mice.

\section{Preparation of tumor cells after in vivo passage}

Briefly, sarcoma L-1 cells from in vitro stock were grafted $\left(10^{6} / 0.1 \mathrm{ml}\right)$ subcutaneously into subscapular region of Balb/c mice. After 14 days, the tumors were excised, cut to smaller pieces, rubbed through sieve, and suspended in $5 \mathrm{ml}$ of PBS. The suspension was left for $10 \mathrm{~min}$ at room temperature. After sedimentation, the supernatant was collected and centrifuged for $10 \mathrm{~min}$ at $300 \mathrm{G}$-force. Obtained sarcoma cells were washed once with PBS for $10 \mathrm{~min}$, then centrifuged at $300 \mathrm{G}$ - force and re-suspended in Parker medium in concentration of $4 \times 10^{6}$ cells $/ \mathrm{ml}$ (for tumor-induced angiogenesis) or $10^{7}$ cells $/ \mathrm{ml}$ (for experiments with tumor growth). Viability of cells was about $95 \%$ of living cells as estimated by trypan blue method.

\section{Subcutaneous tumor growth assay}

Suspensions of sarcoma cells were grafted ( 1 million of cells) subcutaneously into mice. On the day of cells grafting and on the following 13 days mice were fed drugs (with Eppendorf pipette) or water as a control. Mice were observed during these days, with number of appearing tumors noted at 6, 8, 11 and 13 days after grafting. At days 8, 11 and 13 the tumors volume was measured with electronic caliper (The Fowler Ultra-Cal Mark III caliper).

\section{Cutaneous angiogenesis assay - tumor-induced angiogenesis (TIA) test (Fig. 4)}

Cells isolated as described above, in concentration of $2 \times 10^{6}$ per $\mathrm{ml}$ were suspended in Parker medium supplemented with L-glutamine, Hepes buffer, streptomycin $(100 \mu \mathrm{g} / \mathrm{ml})$ and penicillin $(100 \mathrm{U} / \mathrm{ml})$ in the presence of $5 \%$ fetal bovine serum (FBS, Gibco) and without or with the pentoxifylline in concentration $2,5,10,20,50$, and $100 \mu \mathrm{g}$ per $\mathrm{ml}$. The cultures were incubated for $90 \mathrm{~min}$ at $37^{\circ} \mathrm{C}$, equilibrated with a $5 \% \mathrm{CO}_{2} / 95 \%$ air mixture, then washed. Multiple $0.05 \mathrm{ml}$ samples of 200 thousands of cells were injected intradermally into partly shaved, narcotized Balb/c mice (at least 3-4 mice per group). In order to facilitate the localization of cell injection sites later on, the suspension was colored with $0.1 \%$ of trypan blue. After 72 hours, mice were sacrificed with lethal dose of Morbital (Biowet, Puławy). All newly formed blood vessels were identified and counted in dissection microscope, on the inner skin surface, at magnification of $6 \times$, in $1 / 3$ central area of microscopic field. Identification was based on the fact that the new blood vessels are thin, directed to the point of cells injection and (or) differ from the background vasculature in their tortuosity and divarications (Fig. 5).

All experiments were performed in anaesthesia (3.6\% chloral hydrate, Sigma-Aldrich), $0.1 \mathrm{ml}$ per $10 \mathrm{~g}$ of body mass.

\section{Statistical analysis}

Results are expressed as means +/- SEM or as inhibition indices. Statistical evaluation of the results was performed using one-way ANOVA, followed by the Tukey's post-hoc test, two-way ANOVA followed by the Bonferroni test, and $\chi^{2}$ test (Graph Pad Software, Inc., La Jolla, CA, USA), level of significance $\alpha=0.05$ was considered to indicate a statistically significant difference.

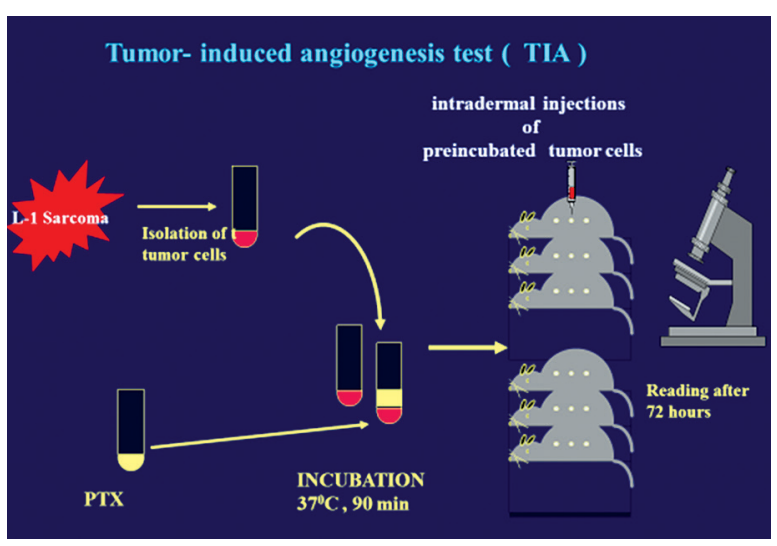

PTX - pentoxifylline

Fig. 4. Schematic test TIA (tumor-induced angiogenesis) 


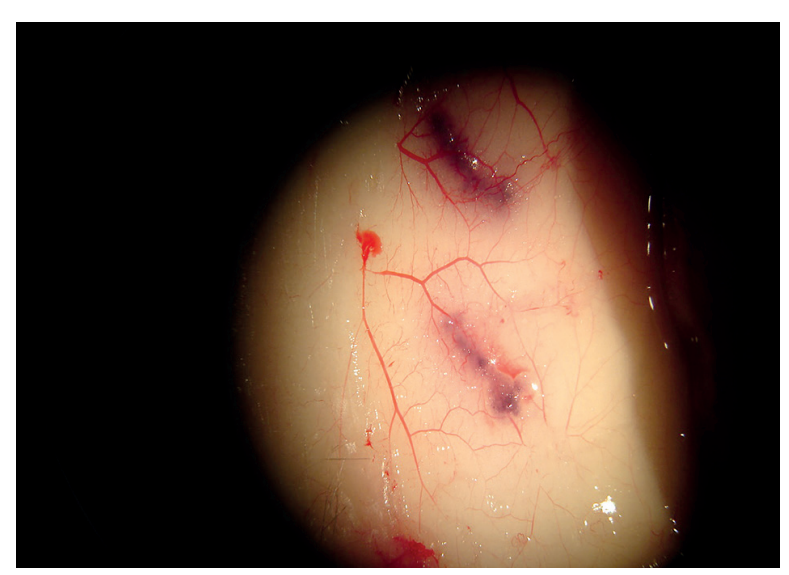

Fig. 5. Typical picture of neovascular reaction 3 days after intradermal injection of tumor cells, seen on the inner side of mouse skin. Note newly-formed thin blood vessels directed to the place of cells' grafting. Magnification $6 \times$

\section{Results}

Results of experiments are shown in Figures 6, 7 and 8 . We obtained highly significant reduction in tumor size in mice which received for two weeks PTX (Fig. 6) and a synergistic effect in animals receiving a mixture of PTX and sulindac (Fig. 7). Synergistic inhibitory effect of PTX and sulindac was expressed as \% of tumors sixth

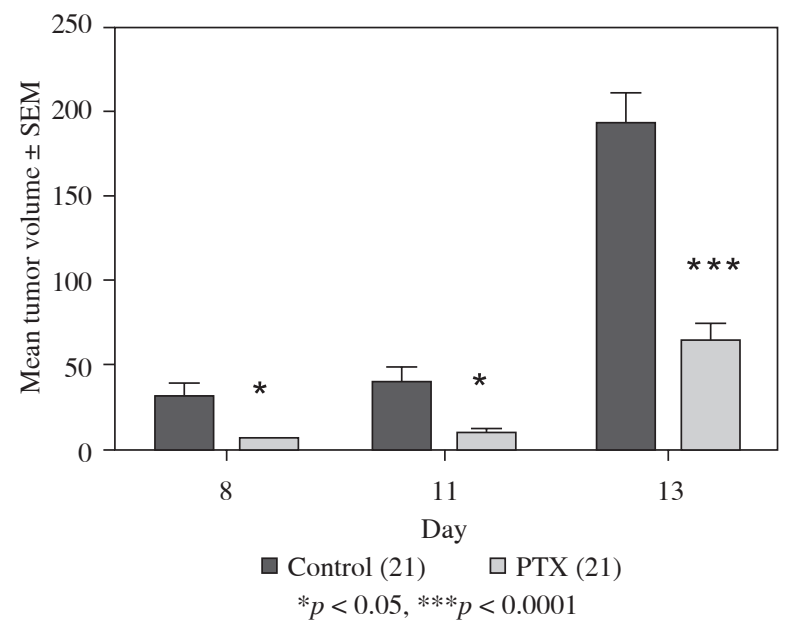

\begin{tabular}{|c|c|c|}
\hline Two-way ANOVA & & \\
\hline Source of Variation & $\%$ of total variation & $p$ value \\
\hline Interaction & 9.33 & $<0.0001$ \\
\hline Drug & 16.07 & $<0.0001$ \\
\hline Time & 42.36 & $<0.0001$ \\
\hline
\end{tabular}

Fig. 6. Mean tumor volume in mice grafted with L-1 sarcoma cells. Mice were fed daily $0.5 \mathrm{mg}$ PTX for 13 days, or water as a control. Number of mice in parentheses and thirteen day after subcutaneous grafting of L-1 sarcoma into syngeneic Balb/c mice. Mice were fed daily PTX $(0.5 \mathrm{mg})$, sulindac $(0.6 \mathrm{mg})$ or both drugs.

Preincubation of tumor cells with PTX resulted in dose-dependent inhibition of their angiogenic activity (Fig. 8).

\section{Discussion}

In recent years one can observe the intensification of research efforts to study methods of cancer treatment. Most of the research is dedicated to the study of mechanisms of tumor formation and therapies that entail the blocking of certain stages of tumor progression or changing of the direction of progression. The studies on the processes of angiogenesis are particularly intensive.

In the present paper we demonstrate for the first time the ability of pentoxifylline to reduce angiogenic activity of Sarcoma L-1 murine cell line in cutaneous angiogenesis test. Moreover, this drug significantly delayed appearance and diminished volume of Sarcoma L-1 tumors in recipient syngeneic Balb/c mice. Synergistic inhibitory effect was also observed for PTX and nonsteroidal anti-inflammatory drug sulindac.

Anti-angiogenic effect of sulindac and its metabolites was described for the first time by Skopinska-Różewska et al. in 1998 [22]. Later papers reported that sulindac and some other NSAIDs induce endothelial cells apoptosis and

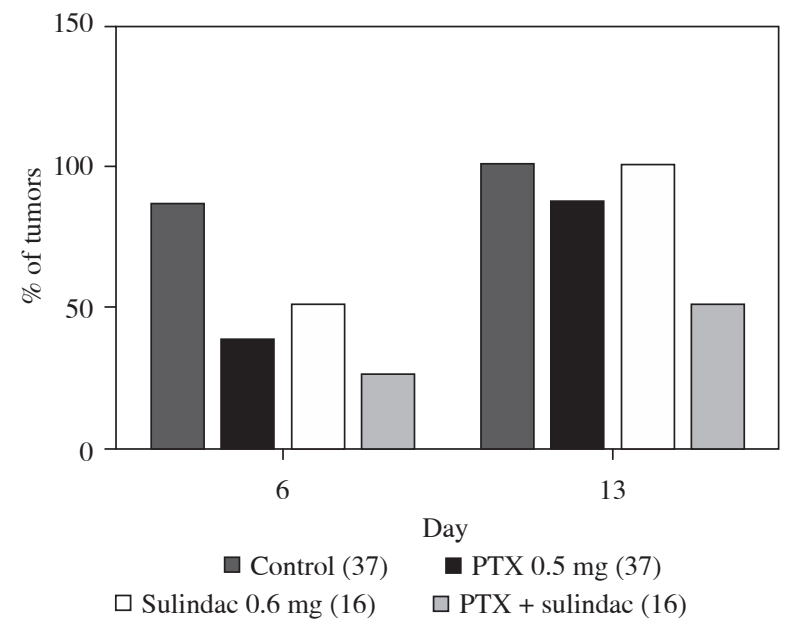

\begin{tabular}{|c|c|}
\hline$\chi^{2}$ & \\
\hline$\chi^{2}, \mathrm{df}$ & $10.42,3$ \\
\hline$p$ value & 0.0153 \\
\hline$p$ value summary & $*$ \\
\hline
\end{tabular}

Fig. 7. Synergistic inhibitory effect of PTX and sulindac expressed as \% of tumors sixth and thirteen day after subcutaneous grafting of L-1 sarcoma into syngeneic Balb/c mice. Mice were fed daily PTX $(0.5 \mathrm{mg})$, sulindac $(0.6 \mathrm{mg})$ or both drugs. Number of mice in parentheses 
endothelial cell cycle arrest $[23,24]$. Synergistic inhibitory effect on tumor growth and angiogenesis in similar murine model we observed previously for sulindac and herbal remedy PERVIVO [25].

Some observations indicate that eicosanoids, such as PGE2, are elevated in various human tumour tissues and can stimulate tumour cell proliferation and regulate their apoptosis. Especially COX-2 is an important agent responsible for the chemopreventive effects of NSAIDs. Sulindac is an anti-inflammatory prodrug converted by the liver enzymes in the body to the active non-steroidal anti-inflammatory metabolites (NSAIDs). This enzymatic prodrug activation to an active sulphide, excreted in the bile and reabsorbed from the intestine, reduces gastrointestinal side effects. It was shown, that sulindac, independently from COX-inhibition, has ability to reduce the growth of polyps in gastrointestinal tract [26]. It exerts also other anti-cancer properties e.g. induces apoptosis in cancer cells [27]. Furthermore may have anti-oxidative properties due to the observation that methionine sulfoxide reductase can reduce sulfoxide group of sulindac. Actually the sulfone metabolite of sulindac, exisulind, is the most studied, for its ability to decrease the risk of different cancers development on various rodent models of carcinogenesis. Numerous epidemiological studies have reported that the long-term use of NSAIDs is associated with a significant decrease in cancer occurrence and delayed progression of cancer disease. The use of NSAIDs has also been linked with reduced risk from cancer-related mortality and distant metastasis. Additionally, the anticancer effect of the agents was found to result partly from their anti-angiogenic action, which, therefore, restricts tumorigenesis. Some authors shown, that sulindac may cause regression of precancerous lesions e.g. it lowers the risk of developing colonic adenomatous polyps [28].

Unfortunately, the prolonged use of NSAIDs for chemoprevention often results in potentially serious side effects related to their cyclooxygenase-inhibitory activity and suppression of prostaglandin synthesis. Nonsteroidal anti-inflammatory drugs display promising anticancer activity, although their toxicity resulting from cyclooxygenase (COX) inhibition limits the clinical use for such chemoprevention. However in some cancers (e.g. in colon tumour cells), studies suggest, that the mechanism may be different - COX independent. Tinsley showed that sulindac sulphide inhibits cyclic guanosine 3'5'-monophosphate (cGMP) phosphodiesterase (PDE) activity in colon tumour cells causing inhibition of growth in vitro and in vivo. Numerous novel applications of PTX have been proposed, among them in cancer therapy. Pentoxifylline has been found to sensitize some cancer cell lines to chemoand radiotherapy, and to improve delivery of chemotherapeutics into the tumor cells.

Pentoxifylline sensitizes human cervical tumor cells to cisplatin-induced apoptosis by suppressing NF- $\kappa \mathrm{B}$ and decreased cell senescence [29-34].

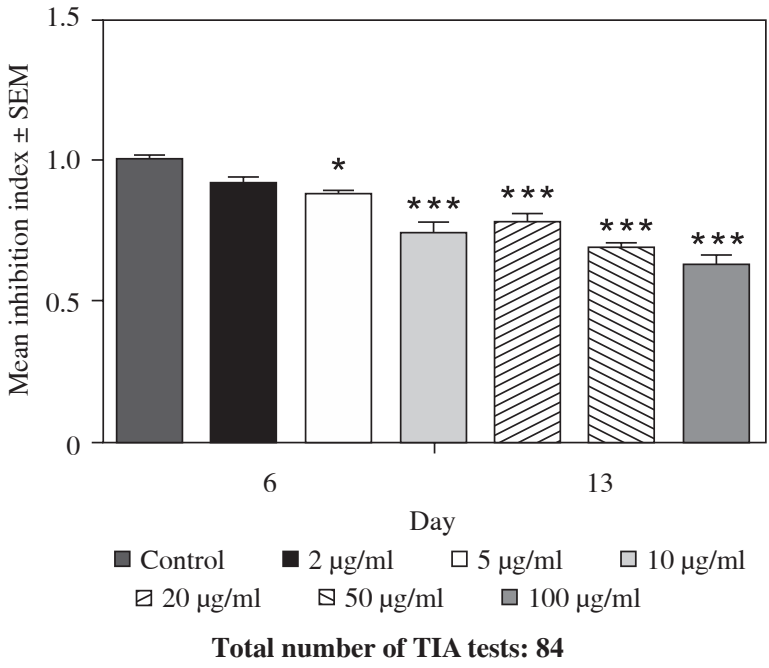

\begin{tabular}{|c|c|}
\hline One-way analysis of variance & \\
\hline$p$ value & $<0.0001$ \\
\hline$p$ value summary & $* * *$ \\
\hline Are means signif. different? $(p<0.5)$ & Yes \\
\hline
\end{tabular}

Fig. 8. The effect of preincubation of sarcoma L-1 cells with PTX on cutaneous neovascular reaction induced by their transplantation to syngeneic Balb/c mice

Gude et al. reported, that the inhibitory effect of PTX on tumor angiogenesis is related to anti-proliferative action on endothelial cells as well as to down-regulation of u-PA secreted by them [35]. Recently, using zebrafish model Nathan et al. studied the expression of adenosine receptors and VEGF during angiogenesis and its inhibition by PTX [36].

In the case of mouse neuroblastoma, PTX had cytostatic effect and exerted an anti-tumor effect on liver metastases following intravenous administration of neuroblastoma cells [37]. In the case of melanoma, PTX inhibited angiogenesis, tumor growth and melanoma-derived metastatic tumor development in lungs. Kamran and Gude identified STAT3 signaling as a target of PTX in its inhibitory action on melanoma tumor growth and angiogenesis [38]. Our present study shows inhibitory effect of PTX on murine sarcoma tumor growth and angiogenesis.

Although most studies show inhibition of tumor growth by PTX, there are also papers that describe the stimulation of tumor growth, but in the case of murine colon adenocarcinoma only. Moreover, PTX promoted development of adenocarcinoma derived metastatic tumors in liver and lungs. The authors attribute this effect to the negative effects of PTX on cytotoxic lymphocytes and disturbance of perforin-dependent pathway [39-42]. Although this model might be unique in its sensitivity to tumor-pro- 
moting effects of PTX, it cannot be excluded that similar effects might occur in some cases of tumors developing in humans. Then, evidently more studies on the problem are necessary.

The authors declare no conflicts of interest.

\section{References}

1. Bałan BJ, Siwicki AK, Pastewka K, et al. (2017): Synergistic activity for some natural and synthetic inhibitors of angiogenesis induced by mice sarcoma L-1 and human kidney cancer cells (RCC). Adv Exper Med Biol, DOI: 10.1007/5584_2017_17.

2. Skopiński P, Żukowska M, Małkowska-Zwierz W, et al. (1993): The effect of TPP, theophylline, and theobromine on the angiogenic activity of mononuclear leukocytes obtained from diabetic patients with proliferative retinopathy. Acta Pol Pharm 50: 409-411.

3. Gil M, Skopińska-Różewska E, Radomska D, et al. (1993): Effect of purinergic receptor antagonists suramin and theobromine on tumor-induced angiogenesis in Balb/c mice. Folia Biol (Praha) 39: 63-68.

4. Skopinska-Rózewska E, Janik P, Przybyszewska M, et al. (1998): Inhibitory effect of theobromine on induction of angiogenesis and VEGF mRNA expression in $v$-raf transfectants of human urethelial cells HCV-29. Int J Mol Med 2: 649-701.

5. Barcz E, Sommer E, Sokolnicka I, et al. (1998): The influence of theobromine on angiogenic activity and proangogenic cytokines production of human ovarian cancer cells. Oncol Rep 5: 517-520.

6. Barcz E, Sommer E, Janik P, et al. (2000): Adenosine receptor antagonism causes inhibition of angiogenic activity of human ovarian cancer cells. Oncol Rep 7: 1285-1291.

7. D'Hellencourt CL, Diaw L, Cornillet P, Guenounou M (1996): Differential regulation of TNF alpha, IL-1 beta, IL-6, IL-8, TNF beta, and IL-10 by pentoxifylline. Int J Immunopharmacol 18: 739-748.

8. Mandell GL (1995): Cytokines, phagocytes, and pentoxifylline. J Cardiovasc Pharmacol 25 (Suppl 2): S20-22.

9. Barros Mendes J, Peixoto Campos P, Rocha MA, Passos Andrad S (2009): Cilostazol and pentoxifylline decrease angiogenesis, inflammation, and fibrosis in sponge-induced intraperitoneal adhesion in mice. Life Sci 84 (15-16): 537-543.

10. Pammi M, Haque KN (2015): Pentoxifylline for treatment of sepsis and necrotizing enterocolitis in neonates. Cochrane Database Syst Rev 3: CD004205.

11. Zein CO, Lopez R, Fu X, et al. (2012): Pentoxifylline decreases oxidized lipid products in nonalcoholic steatohepatitis: New evidence on the potential therapeutic mechanism. Hepatology (Baltimore, Md) 56: 1291-1299.

12. Li H, Tan G, Tong L, et al. (2016): Pentoxifylline inhibits pulmonary inflammation induced by infrarenal aorticcross-clamping dependent on adenosine receptor A2A. Amer J Translational Res 8: 2210-2221.

13. Schulzke SM, Kaempfen S, Patole SK (2014): Pentoxifylline for the prevention of bronchopulmonary dysplasia in preterm infants. Cochrane Database Syst Rev 11: CD010018.

14. Mohammadpour AH, Falsoleiman H, Shamsara J, et al. (2014): Pentoxifylline decreases serum level of adhesion molecules in atherosclerosis patients. Iranian Biomed J 18: 23-27.
15. Thursz MR, Richardson P, Allison M, et al. (2015): Prednisolone or pentoxifylline for alcoholic hepatitis. N Engl J Med 372: 1619-1628

16. Vege SS, Atwal T, Bi Y, et al. (2015): Pentoxifylline treatment in severe acute pancreatitis: a pilot, double-blind, placebo-controlled, randomized trial. Gastroenterology 149: 318-320.

17. Sunil VR, Vayas KN, Cervelli JA, et al. (2014): Pentoxifylline Attenuates Nitrogen Mustard-induced Acute Lung Injury, Oxidative Stress and Inflammation. Exp Mol Pathol 97: 89-98.

18. Rainsford KD (2010): Cardiovascular adverse reactions from NSAIDs are more than COX-2 inhibition alone. Rheumatology (Oxford) 49: 834-836,

19. Kearney PM, Baigent C, Godwin J, et al. (2006): Do selective cyclo-oxygenase- 2 inhibitors and traditional non-steroidal anti-inflammatory drugs increase the risk of atherothrombosis? Meta-analysis of randomized trials. BMJ 332: 1302-1305.

20. Graham DJ (2006): COX-2 inhibitors, other NSAIDs, and cardiovascular risk; the seduction of common sense. JAMA 296: 1653-1656.

21. Koren G, Florescu A, Costei AM, et al. (2006): Nonsteroidal anti-inflammatory drugs during third trimester and the risk of premature closure of the ductus arteriosus: a meta-analysis. Ann Pharmacother 40: 824-829.

22. Skopinska-Różewska E, Piazza GA, Sommer E, et al. (1998): Inhibition of angiogenesis by sulindac and its sulfone metabolite (FGN-1): a potential mechanism for their antineoplastic properties. Int J Tissue Reactions 20: 85-89.

23. Flis S, Sołtysiak-Pawluczuk D, Jędrych A, et al. (2006): Antiangiogenic effect of sulindac sulfide could be secondary to induction of apoptosis and cell cycle arrest. Anticancer Res 26: 3033-3041.

24. Liou JY, Wu CC, Chen BR, et al. (2008): Nonsteroidal anti-inflammatory drugs induced endothelial apoptosis by perturbing peroxisome proliferator-activated receptor - transcriptional pathway. Mol Pharmacol 74: 1399-1406.

25. Skopiński P, Bałan BJ, Kocik J, et al. (2013): Inhibitory effect of herbal remedy PERVIVO and anti-inflammatory drug sulindac on L-1 sarcoma tumor growth and tumor angiogenesis in Balb/c mice. Mediators Inflamm. Article ID 289789 , DOI: dx.doi.org /10.1155/ 2013/ 289/789.

26. Lynch PM (2016): Chemoprevention of familial adenomatous polyposis. Fam Cancer 15: 467-475.

27. Gong EY, Shin YJ, Hwang IY, et al. (2016): Combined treatment with vitamin $\mathrm{C}$ and sulindac synergistically induces p53and ROS-dependent apoptosis in human colon cancer cells. Toxicol Lett 258: 126-133.

28. Haanen C (2001): Sulindac and its derivatives: a novel class of anticancer agents. Curr Opin Investig Drugs 2: 677-683

29. Samadder NJ, Neklason DW, Boucher KM, et al. (2016): Effect of Sulindac and Erlotinib vs Placebo on Duodenal Neoplasia in Familial Adenomatous Polyposis: A Randomized Clinical Trial. JAMA 315: 1266-1275.

30. Tinsley HN, Gary BD, Thaiparambil J, et al. (2010): Colon tumour cell growth-inhibitory activity of sulindac sulfide and other nonsteroidal anti-inflammatory drugs is associated with phosphodiesterase 5 inhibition. Cancer Prev Res (Phila) 3: 1303-1313.

31. Li YX, Sun LQ, Weber-Johnston K, et al. (1999): Potentiation of cytotoxicity and radiosensitization of (E)-2-deoxy-2 (fluoromethylene) cytidine by pentoxifylline in vitro. Int J Cancer 80: 155-160. 
32. Kim SH, Khil MS, Ryu S, Kim JH (1993): Enhancement of radiation response on human carcinoma cell lines in culture by pentoxifylline. Int J Radiat Oncol 25: 61-65.

33. Mastrandrea NJ (2014): Pentoxifylline as an adjuvant treatment in renal cell carcinoma. http://hdl.handle.net/10150/ 337293.

34. Hernandez-Florez G, Ortiz-Lazareno PC, Lerma-Diaz JM, et al. (2011): Pentoxifylline sensitizes human cervical tumor cells to cisplatin-induced apoptosis by suppressing NF-kappa $\mathrm{B}$ and decreased cell senescence. BMC Cancer 11: 483.

35. Gude RP, Binda MM, Boquete AL, Bonfil RD (2001): Inhibition of endothelial cell proliferation and tumor-induced angiogenesis by pentoxifylline. J Cancer Res Clin Oncol 127: 625-630.

36. Nathan JR, Lakshmanan G, Michael FM, et al. (2016): Expression of adenosine receptors and VEGF during angiogenesis and its inhibition by pentoxifylline - a study using zebrafish model. Biomed Pharmacother 84: 1406-1418.

37. Amirkhosravi A, Warnes G, Biggerstaff J, et al. (1997): The effect of pentoxifylline on spontaneous and experimental metastasis of the mouse neuro2a neuroblastoma. Clin Exp Metast 15: 453-461

38. Kamran MZ, Gude ROP (2013): Pentoxifylline inhibits melanoma tumor growth and angiogenesis by targeting STAT3 signaling pathway. Biomed Pharmacother 67: 399-405.

39. Lazarczyk M, Grzela T, Niderla J, et al. (2004): Differential influence of pentoxifylline on murine colon adenocarcinoma- and melanoma- derived metastatic tumor development in lungs. Oncol Rep 11: 1121-1125.

40. Grzela T, Lazarczyk M, Niderla J, et al. (2003): Pentoxifylline promotes development of murine colon adenocarcinoma-derived metastatic tumors in liver. Oncol Rep 10: 1805-1809.

41. Lazarczyk M, Grzela T, Niderla J, et al. (2003): Pentoxifylline inhibits leukocyte infiltration and splenocyte cytotoxicity against murine colon adenocarcinoma. Oncol Rep 10: 839-843.

42. Lazarczyk M, Grzela T, Korczak-Kowalska G, et al. (2002): Pentoxifylline inhibits perforin-dependent natural cytotoxicity in vitro. Oncol Rep 9: 423-426. 